\title{
Characterization and optical studies of PVP-capped silver nanoparticles
}

\author{
Ali Mirzaei ${ }^{1} \cdot$ Kamal Janghorban $^{1} \cdot$ Babak Hashemi $^{1} \cdot$ Maryam Bonyani $^{1} \cdot$ \\ Salvatore Gianluca Leonardi ${ }^{2} \cdot$ Giovanni Neri $^{2}$
}

Received: 9 October 2016/Accepted: 14 November 2016/Published online: 24 November 2016

(C) The Author(s) 2016. This article is published with open access at Springerlink.com

\begin{abstract}
In this study, the size-controlled synthesis of silver nanoparticles (Ag NPs) via chemical reduction method by $\mathrm{NaBH}_{4}$ as a reducing agent and poly(vinyl pyrrolidone) or PVP as a stabilizing agent is reported. Changing of ratios between reducing agent and stabilizing agent relative to $\mathrm{AgNO}_{3}$-optimized conditions for synthesis of stable Ag NPs was studied. The formation of Ag NPs was tracked by UV-Vis spectroscopy, X-ray diffraction (XRD), X-ray photoelectron spectroscopy (XPS), and photoluminescence (PL) spectroscopy. Particle size distribution was studied by particle size analyzer, and the morphology was examined by scanning electron microscopy (SEM) and transmission electron microscopy (TEM). The optical properties of the synthesized Ag NPs were also investigated. The optimized Ag NPs were very stable even after 1 month that was due to effective stabilization by PVP molecules. The mechanism of Ag NPs formation and stabilization is discussed in detail.
\end{abstract}

Keywords Ag NPs · PVP - Chemical reduction - Optical properties

Ali Mirzaei

alisonmirzaee@yahoo.com

1 Department of Materials Science and Engineering, Shiraz University, Shiraz, Iran

2 Department of Engineering, University of Messina, Contrada di Dio, 98166 Messina, Italy

\section{Introduction}

$\mathrm{Ag}$ nanoparticle (Ag NPs) is clusters of silver atoms of $1-100 \mathrm{~nm}$ at least in one dimension [1,2]. Owing to their unique physical and chemical properties, they are widely used in various areas of science and technology, such as surface-enhanced Raman spectroscopy [3], catalysts [4], anti-bacterial materials [5], sensors [6], lubricating materials [7], and so on, with exponentially increasing production. As the properties of Ag NPs depend on their sizes, up to now, various methods, such as spray pyrolysis synthesis [8], microwave irradiation synthesis [9], DC arc thermal plasma synthesis [10], chemical synthesis [11], hydrothermal synthesis [12], UV irradiation synthesis [13], sonochemical synthesis [14], laser ablation synthesis [15], thermal decomposition synthesis [16], atom beam-sputtering synthesis [17], and so forth, have been employed to prepare Ag NPs with different sizes and shapes.

Among the various methods for synthesis of Ag NPs, the wet chemical reduction method is the most popular synthesis route, thanks to its simplicity, low cost and ability to produce large quantities of $\mathrm{Ag}$ NPs [1]. In a typical chemical reduction process, a reducing agent, such as $\mathrm{NaBH}_{4}$ [18], hydrazine [19], triethanolamine [20], L-ascorbic acid [21], glucose [22], and aniline [11], and a protective agent, such as poly(vinyl alcohol) (PVA) [23], poly(vinyl pyrrolidone) (PVP), cellulose [24], alkanethiols [25], alkylamines [26], dodecanethiol [27], and carboxylicacids [28], help to obtain Ag NPs with various sizes [29].

However, almost all of above studies mostly studied the effect of different reducing agents and stabilizing agents on the final morphology of Ag NPs [30, 31], while the control of particle size using the chemical reduction route is rarely reported. For example, Bastús et al. [32] reported the possibility to synthesize highly monodisperse Ag NPs from 10 to 
$200 \mathrm{~nm}$ by the precise kinetic control of the reaction, in particular the use of two reducing agents, i.e., sodium citrate and tannic acid, the temperature of the solution, and the Ag seeds to $\mathrm{Ag}$ precursor ratio. $\mathrm{Li}$ et al. [33] reported synthesis of monodisperse, quasi-spherical silver nanocrystals directly in water via adding the aqueous solution of a mixture of $\mathrm{AgNO}_{3}$, sodium citrate, and potassium iodide into the boiling aqueous solutions of ascorbic acid. In addition, Liu et al. [34] demonstrated a successful one-step seeded growth route to $\mathrm{Ag}$ quasi-nanoparticles of uniform sizes in the range of $19-140 \mathrm{~nm}$, by carefully tune the kinetics of the seeded growth reaction to an appropriate level by the means of coordinating acetonitrile to an Ag (I) salt and adjusting the reaction temperature.

In this paper, a simple and efficient chemical reduction method was explored to synthesize the size-controlled Ag NPs. The formation of Ag NPs and their electrical and optical properties are investigated and discussed in detail.

\section{Experiment}

\section{Ag NP synthesis}

The starting materials were silver nitrate $\left(>99.9 \%, \mathrm{AgNO}_{3}\right)$ sodium borohydride $\left(>98 \%, \mathrm{NaBH}_{4}\right)$ and PVP (M.W. $>$ $1.3 \times 10^{5}$ ), purchased from Merck (Germany). All the chemicals were used without further purification, and redistilled water was used to prepare all the solutions.

Figure 1 schematically shows the synthesis procedure, which refers to Creighton's method that uses sodium borohydride as the reducing agent [35]. The solutions of PVP and $\mathrm{AgNO}_{3}$ were prepared separately by dissolving appropriate amounts of $\mathrm{AgNO}_{3}$ (10 and $25 \mathrm{mM} \mathrm{AgNO}_{3}$ in $10 \mathrm{ml}$ ) and PVP in distilled water and in well-cleaned dry beakers at room temperature. With the aim of preparing stable Ag NPs with different sizes, several PVP (based on the weights of a PVP unit 111) to $\mathrm{AgNO}_{3}$ ratios $(S)$ were tested to determine the optimal conditions (Table 1). Then, two solutions were mixed together and stirred for $30 \mathrm{~min}$, at an ice-cold bath. In a separate flask, appropriate amount of $\mathrm{NaBH}_{4}$ was dissolved in the distilled water at zero temperature. The ratio of $\mathrm{NaBH}_{4}$ to $\mathrm{AgNO}_{3}(R)$ was varied to find the best results (Table 1). Then, reducing agent solution was added to $\mathrm{Ag}^{+}-\mathrm{PVP}$ solution dropwise to reduce the Ag ions to Ag NPs. A transparent bright yellow color was observed immediately due to the formation of the silver colloids. The solutions were kept in a dry place study their stabilities over months. In addition, the necessary characterizations were done for successfully synthesized Ag NPs.

\section{Characterization}

Characterization of Ag NPs was achieved by different techniques. X-ray diffraction analysis (XRD) was performed using a Philips X-Pert diffractometer operating with monochromatic $\mathrm{CuK} \alpha(\lambda=1.54056 \AA)$ radiation at $40 \mathrm{kV}$ and $30 \mathrm{~mA}$. The XRD pattern was recorded at room temperature at a scan rate $0.05^{\circ} \mathrm{s}$ and $2 \theta$ from $30^{\circ}$ to $90^{\circ}$.

Morphological analysis was carried out using scanning electron microscopy (SEM) using a JEOL 5600 LV instrument operating with a $20 \mathrm{kV}$ accelerating voltage. Crystallinity and morphological studies of synthesized powders were performed with a JEOL JEM 2010 electron microscope $\left(\mathrm{LaB}_{6}\right.$ electron gun) operating at $200 \mathrm{kV}$.

$\mathrm{X}$-ray photoelectron spectroscopy (XPS) was employed to determine the composition of Ag NPs. XPS was performed on an ESCALAB MKII X-ray photoelectron spectrometer (VG Instruments, CA, USA), using nonmonochromatized $\mathrm{Mg}-\mathrm{K} \alpha \mathrm{X}$-rays as the excitation source. The binding energies for the sample were calibrated by setting the measured binding energy of $\mathrm{C} 1 \mathrm{~s}$ to $284.60 \mathrm{eV}$.

The photoluminescence (PL) spectrum of the Ag NPs was measured on a Hitachi F-4500 FL spectrophotometer with an Xe lamp with the excitation wavelength of $355 \mathrm{~nm}$
Fig. 1 Schematic representation of different steps of Ag NPs synthesis

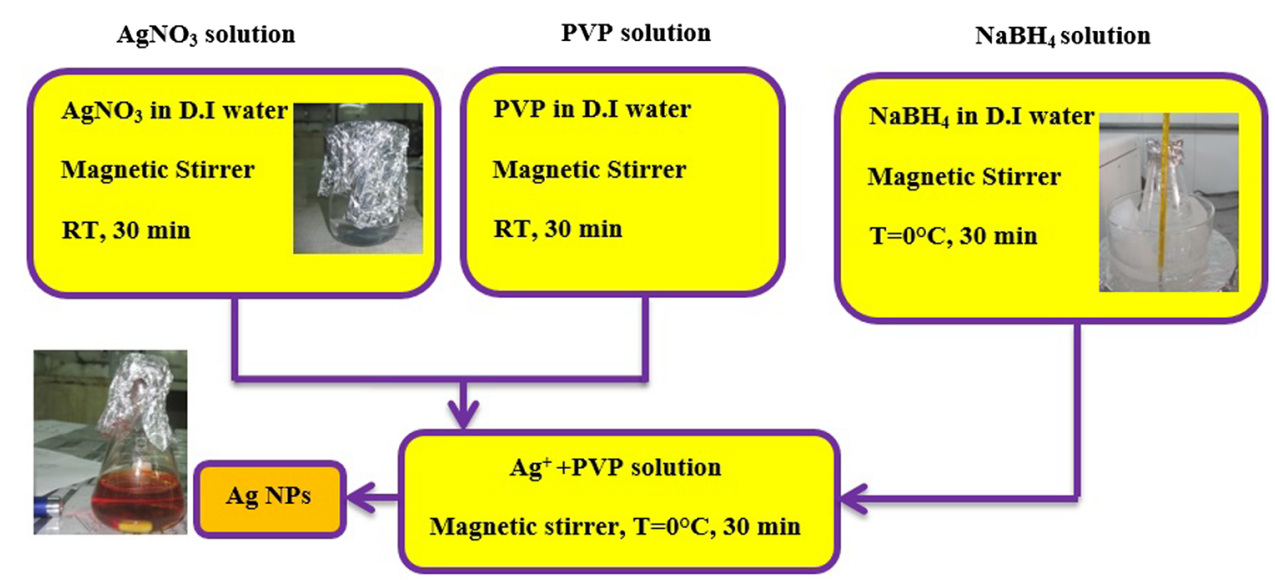


Table 1 Overview of the different experiment parameters performed for the synthesis of Ag NPs during this work

\begin{tabular}{llllll}
\hline No & {$\left[\mathrm{AgNO}_{3}\right] \mathrm{mM}$ in $10 \mathrm{ml}$} & {$[\mathrm{SBH}] /\left[\mathrm{AgNO}_{3}\right]$} & {$[\mathrm{PVP}] /\left[\mathrm{AgNO}_{3}\right]$} & $T\left({ }^{\circ} \mathrm{C}\right)$ & Appearance and stability \\
\hline 1 & 10 & 0.5 & 0 & Ice-cold & Black, unstable \\
2 & 10 & 0.7 & 0 & Ice-cold & Black, unstable \\
3 & 10 & 1 & 0 & Ice-cold & Black, unstable \\
4 & 10 & $1\left(\right.$ aged $\left.\mathrm{NaBH}_{4}\right)$ & 0 & Ice-cold & Black, unstable \\
5 & 10 & 1.3 & 0 & Ice-cold & Black, unstable \\
6 & 10 & 0.7 & 0 & Ice-cold & Black, unstable \\
7 & 10 & 0.7 & 0.5 & Ice-cold & Yellow, stable \\
8 & 10 & 0.7 & 1 & Ice-cold & Yellow, stable \\
9 & 25 & $0.7\left(\right.$ aged $\left.\mathrm{NaBH}_{4}\right)$ & 0.5 & Ice-cold & Gray, unstable \\
10 & 25 & 0.7 & 0.5 & Ice-cold & Yellow, stable \\
11 & 25 & 0.7 & 1.5 & Ice-cold & Yellow, stable \\
12 & 25 & 0.7 & 3 & Ice-cold & Yellow, stable \\
13 & 25 & 0.7 & 0 & RT & Gray, unstable \\
14 & 25 & 0.7 & 1.5 & RT & Gray, unstable \\
15 & 25 & 0.7 & 3 & RT & Gray, unstable \\
\hline
\end{tabular}

and with the wavelength-scanning mode at room temperature in the air.

Thermal analysis was carried out on a "Mettler Toledo" thermal gravimetric analyzer. Analysis was performed in the presence of $\mathrm{N}_{2}$, in the temperature range between 25 and $600{ }^{\circ} \mathrm{C}$, with a heating rate of $10^{\circ} \mathrm{C} / \mathrm{min}$.

Optical absorbance of Ag NPs was recorded with a $1 \mathrm{~cm}$ path length quartz cell using a UV-Vis spectrophotometer (Perkin-Elmer Lambda 2 spectrophotometer) as a function of wavelength in the range from 200 to $800 \mathrm{~nm}$ with a $1 \mathrm{~nm}$ resolution.

\section{Results and discussions}

\section{Parameters' optimization for the synthesis of $\mathrm{Ag}$ NPs}

The reduction of $\mathrm{Ag}$ ions $\left(\mathrm{Ag}^{+}\right)$to $\mathrm{Ag}$ NPs was roughly monitored by visual inspection of the solution. Solutions of colloidal Ag NPs have distinctive yellow color arising from their tiny dimensions. Since $\mathrm{Ag}^{+}$does not have any color, therefore, the formation of Ag NPs has been observed by a change in their color. The addition of $\mathrm{AgNO}_{3}$ solution to distilled water produces a colorless precursor solution. Its UV-Vis spectrum shows a sharp peak at $300 \mathrm{~nm}$ (Fig. 2), which is associated with $\mathrm{Ag}^{+}$ions in the solution. This is the first stage of the $\mathrm{AgNO}_{3}$ reduction reaction, which is dissociated into $\mathrm{Ag}^{+}$and $\mathrm{NO}_{3}{ }^{-}$ions.

The borohydrides, such as $\mathrm{NaBH}_{4}$, are very strong reducing agents, and can reduce most metal salts to elemental metals. The chemical reaction for reduction of $\mathrm{AgNO}_{3}$ in the presence of $\mathrm{NaBH}_{4}$ is as follows [36]:

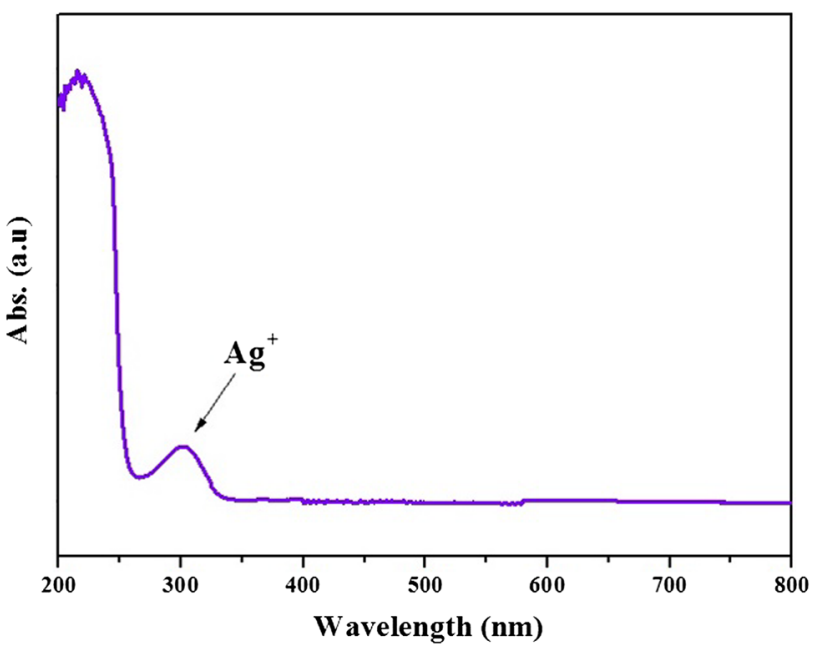

Fig. $2 \mathrm{UV}-\mathrm{Vis}$ spectrum of $\mathrm{AgNO}_{3}$ in water

$\mathrm{AgNO}_{3} \rightarrow \mathrm{Ag}^{+}+\mathrm{NO}_{3}^{-}$

$\mathrm{Ag}^{+}+\mathrm{BH}_{4}^{-}+3 \mathrm{H}_{2} \mathrm{O} \rightarrow \mathrm{Ag}+\mathrm{H}_{3} \mathrm{BO}_{3}+\frac{7}{2} \mathrm{H}_{2}$.

Hydrogen gas is produced by the reduction of silver ions as well as the slow reduction of water by the sodium borohydride at zero temperature:

$\mathrm{BH}_{4}^{-}+3 \mathrm{H}_{2} \mathrm{O} \rightarrow \mathrm{H}_{2} \mathrm{BO}_{3}^{-}+4 \mathrm{H}_{2}(\mathrm{~g})$.

Cloutier et al. [37] reported that the solutions of $\mathrm{NaBH}_{4}$ contain certain amount of sodium hydroxide as a result of the $\mathrm{NaBH}_{4}$ hydrolysis followed by the hydrolysis of sodium metaborate. Furthermore, $\mathrm{NaBH}_{4}$ hydrolysis rate slows down with time because of the increasing concentration of the sodium hydroxide:

$\mathrm{NaBH}_{4}+2 \mathrm{H}_{2} \mathrm{O} \rightarrow \mathrm{NaBO}_{2}+4 \mathrm{H}_{2}$ 
$\mathrm{NaBO}_{2}+\mathrm{H}_{2} \mathrm{O} \rightarrow \mathrm{NaOH}+\mathrm{H}_{3} \mathrm{BO}_{3}$.

Therefore, ageing time of $\mathrm{NaBH}_{4}$ solutions is a crucial problem, so in all cases, before each set of experimental runs, fresh ice-cold $\mathrm{NaBH}_{4}$ solutions were prepared.

Particle formation in the silver-borohydride system follows three distinct stages. First, upon mixing, the reaction between borohydride and silver occurs rapidly, resulting in the formation of small particles $(2-3 \mathrm{~nm})$. In the second stage, these particles grow to achieve sizes of 8-20 nm. In the final stage, the borohydride is consumed by reaction with water. This results in the loss of $\mathrm{BH}_{4}{ }^{-}$and the solution passing from a reducing to an oxidizing environment. The resulting changes in pair potential can drive the particle to aggregates [38].

When sodium borohydride was used for reduction of silver, the reducing reaction was very intense, and in the absence of a protective dispersing agent, the resulting particle sizes would increase as a result of agglomeration effects; therefore, PVP as a surfactant was used to prevent growth of Ag NPs.

A summary of the Ag NPs synthesis experiments performed in this work is listed in Table 1. Without PVP, all
Ag colloids at zero temperature and room temperature were unstable and, therefore, not appropriate for further studies. In addition, $\mathrm{Ag} \mathrm{NPs}$ prepared with aged $\mathrm{NaBH}_{4}$ resulted in the formation of unstable colloids that the reason for this is formation of sodium hydroxide according to equations of (4) and (5). However, when PVP was added as stabilizer, it resulted in formation of stable Ag NPs. Zero temperature was chosen for synthesis, because at room temperature, the particles were grown more rapidly, and aggregation took place at a higher rate, resulting in formation of unstable $\mathrm{Ag}$ NPs. According to obtained results and based on stability of Ag NPs over time, these parameters were chosen to prepare $\mathrm{Ag}$ NPs: concentration of $\mathrm{AgNO}_{3}=25 \mathrm{mM}$, $R\left(\left[\mathrm{NaBH}_{4}\right] /\left[\mathrm{AgNO}_{3}\right]\right)=0.7, S\left([\mathrm{PVP}] /\left[\mathrm{AgNO}_{3}\right]\right)=0.5$, 1.5, and 3 , and $T=0{ }^{\circ} \mathrm{C}$.

\section{Characterization of synthesized Ag NPs}

SEM micrographs of synthesized Ag NPs are shown in Fig. $3 \mathrm{a}$ and $\mathrm{b}$ for $\mathrm{Ag}$ NPs with $S=2.5$ and $S=3$, respectively, where almost spherical morphology of $\mathrm{Ag}$ NPs can be observed. The particle size in these figures can
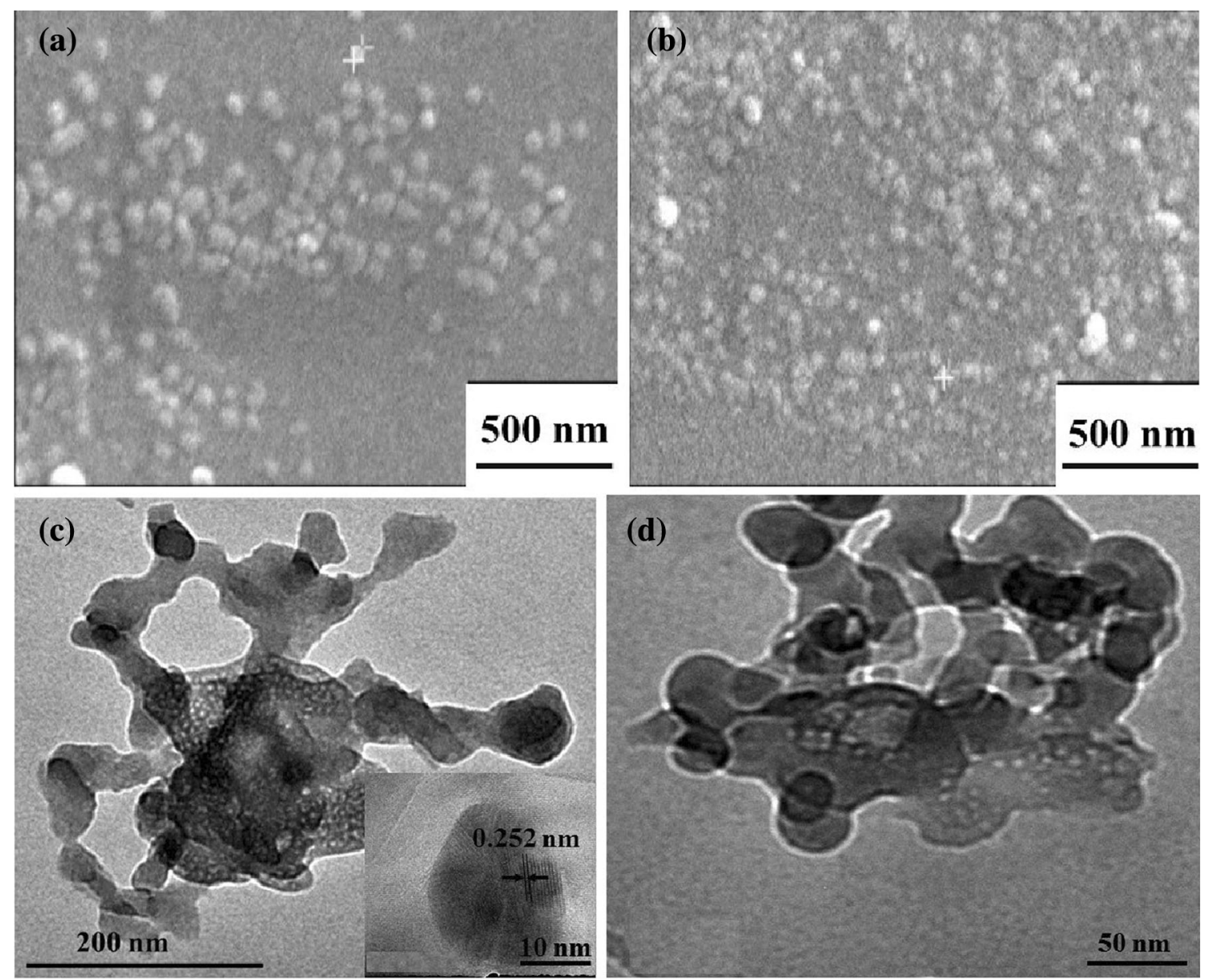

Fig. 3 SEM images of Ag NPs after drying a $S=1.5$, b $S=3$ TEM micrographs, $\mathbf{c} S=1.5$ (inset: HRTEM image), and $\mathbf{d} S=3$ 
Fig. 4 Particle size distribution of Ag NPs with $R=0.7$ and different values of $S$
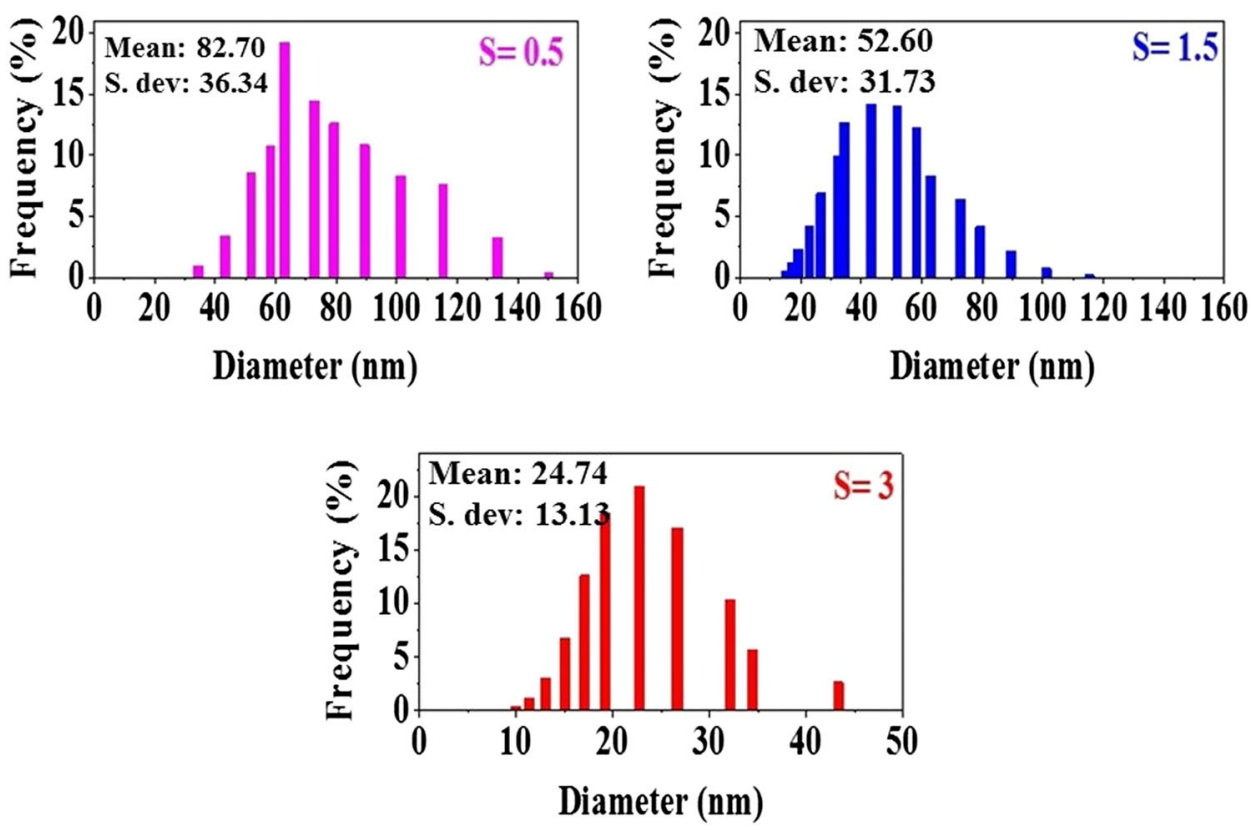

be roughly estimated $75-100$ and $40-80 \mathrm{~nm}$. To see if the PVP is presented around Ag NPs, TEM analysis was performed and TEM micrographs are presented in Fig. 3c and $\mathrm{d}$ for $S=2.5$ and $S=3$, respectively, where PVP around the Ag NPs is clearly visible. The HRTEM micrograph in the inset of Fig. 3c confirms the crystalline nature of synthesized Ag NPs, and lattice spacing of $0.252 \mathrm{~nm}$ can be attributed to the (111) planes of Ag NPs. Figure 4 shows particle size distribution of Ag NPs at fixed $R,(0.7)$ and different values of $\mathrm{S}$. It is worthy to note that the synthesis procedure was very sensitive to change of amount of reducing agent, and in case of $R<0.7$, the reduction of $\mathrm{Ag}$ NPs was not completed, and in case of $R>0.7$, the synthesized Ag NPs agglomerated instantly. Therefore, $R=0.7$ was chosen for synthesis procedure and amount of $S$ was changed. As it can be seen, in general, with increase of $S$, particle sizes decrease. In case of Ag NPs with $S=0.5$, broad particle size distribution $(\sim 30$ to $150 \mathrm{~nm})$ was observed, which was due to insufficient capping of PVP on the surfaces of Ag NPs. However, with increase of $S$ to 1.5 , particle size distribution was spanned from $10 \mathrm{~nm}$ to about $120 \mathrm{~nm}$. The smallest particles were obtained in Ag NPs with $S=3$, where particle size distribution was narrow and spanned from 10 to $45 \mathrm{~nm}$. As shown in Fig. $4 \mathrm{c}$, the mean of particles for this sample is $\sim 25$ which is smaller than other samples. Even though there are some particles with sizes around $10 \mathrm{~nm}$ in the samples with $S=3$, the relatively smaller particle sizes reported in the literatures [32-34], can be related to the use of PVP with different molecular weights as well as use of different reducing agents. To obtain more smaller Ag NPs, higher amount of PVP with different molecular weights (to prevent high viscosity of solution) can be used. When $S$ was above 3 , the viscosity of the solution dramatically increased, and thus, $\mathrm{S}$ did not increase above 3 . The crystallinity of prepared Ag NPs with $S=3$ and $R=0.7$ was investigated by XRD (Fig. 5). It is clearly observed that all the diffraction peaks with $2 \theta$ values of $38.2^{\circ}, 44.35^{\circ}, 64.5^{\circ}$, $77.4^{\circ}$, and $81.57^{\circ}$ can be indexed as the (111), (200), (220), (311), and (222) crystal planes of the face-centered-cubic (fcc) phase of the silver and no trace of $\mathrm{Ag}_{2} \mathrm{O}$ or $\mathrm{AgO}$ was found. Therefore, as-synthesized Ag NPs have high purity, and neither silver compound nor impurity has been intermixed in. At the same time, diffraction peaks indicate good crystallinity of ultrafine silvers. The lattice constant ' $a$ ' calculated from the XRD pattern for dried Ag NPs is $4.0845 \AA$, a value, which is in a close agreement with previously reported data in the literature for silver ( $a=4.086 \AA$, JCPDS 04- 0783). The relatively broad

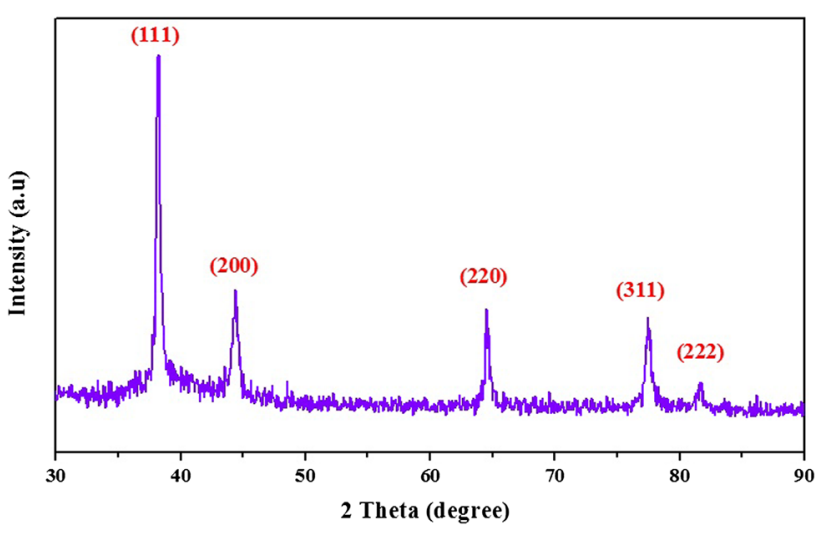

Fig. 5 XRD pattern of Ag NPs 


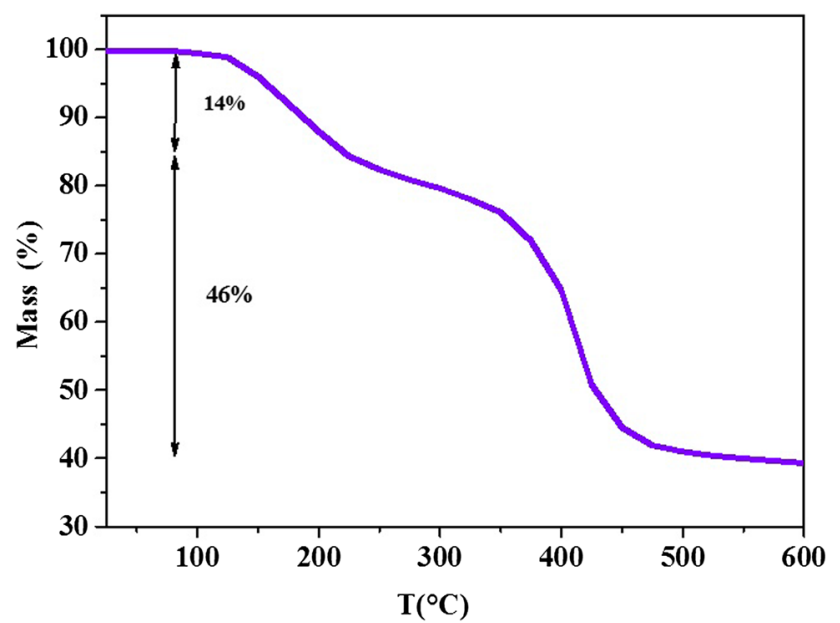

Fig. 6 TGA curve of PVP-capped Ag NPs

peaks indicate the ultrafine average size of products. From the full-width at half-maximum of diffraction peaks, the average crystallite size of Ag NPs has been calculated using Debye-Scherrer equation [39]:

$D=\frac{C \lambda}{\beta \cos \theta}$

where $D$ is crystal size ( $⿱ \dot{\mathrm{A}}), C$ is the shape factor that was taken equal to $0.94, \lambda$ is the wavelength of $\mathrm{X}$-ray used (1.5418 $\AA$ ), $\beta$ is full-width at half-maximum (FWHM) in radians, and $\theta$ is Bragg's diffraction angle for the peak in degrees. The grain size of Ag NPs has been found in the range of $\sim 18 \mathrm{~nm}$.

Figure 6 shows the TGA curve of PVP-capped Ag NPs with $S=3$ and $R=0.7$. Very small mass loss before $100{ }^{\circ} \mathrm{C}$ is due to desorption of adsorbed water on the surface of Ag NPs. The mass loss from 100 to $\sim 200{ }^{\circ} \mathrm{C}$ is attributed to the evaporation of low-molecular weight molecules which were covered Ag NPs. Mass loss observed from $\sim 200$ to $430{ }^{\circ} \mathrm{C}$ corresponds to the burning of organic species from capping layer (PVP). Above $460{ }^{\circ} \mathrm{C}$, the TGA curve tends to be slowly smooth, reaching an almost constant weight. The total mass loss was about $60 \%$, which confirms that the Ag NPs are coated with PVP.

\section{Stability of Ag NPs}

The ability to store chemically synthesized NPs for later use is beneficial to many applications. The stability of $\mathrm{Ag}$ NPs was investigated by monitoring the color of the reaction mixture and measuring the absorption spectra. The results obtained indicate that there is no obvious difference in position and symmetry of absorption peak during the initial 7 days (Fig. 7). After 1 month, the position of the peak has a small shift (from 443 to $448 \mathrm{~nm}$ ), suggesting the

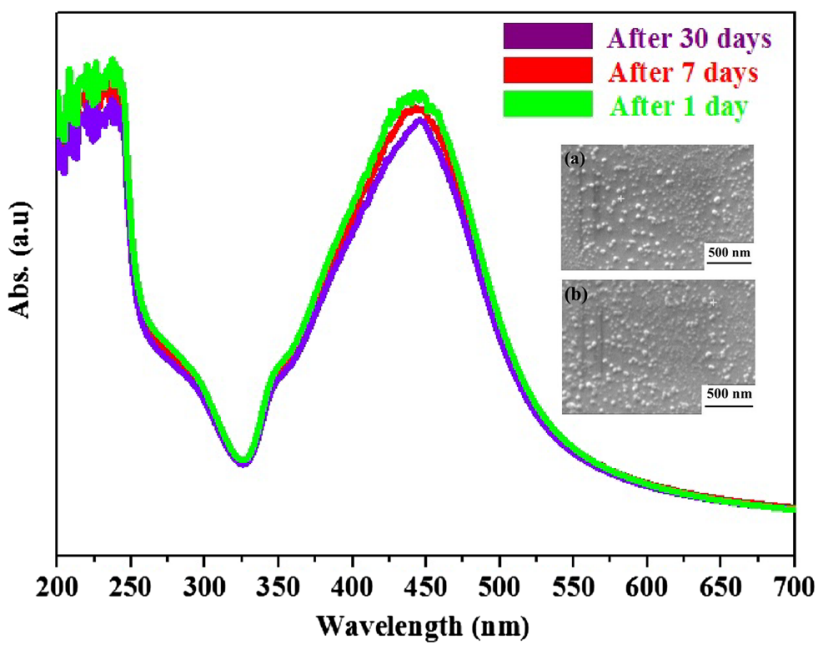

Fig. 7 UV-Vis spectra of Ag NPs after 1, 7, and 30 days. Inset a SEM micrograph after 7 days and b SEM micrograph after 30 days

formation of slightly larger particles without any aggregation. Insets (a) and (b) in Fig. 7 show the SEM images, where the particle sizes did not changes in comparison with fresh colloids (Fig. 3d). Thus, colloidal silver can remain stable at room temperature for as long as several weeks or months. The reason for the stability of the Ag NPs is effective stabilization of Ag NPs due to the presence of PVP. Figure 8 shows stability of Ag NPs during 90 days, where after 90 days, color of Ag NPs was gradually turned into gray, indicating formation of bigger Ag particles and breakdown of stability. As the particles destabilize, the original extinction peak will decrease in intensity (due to the depletion of stable nanoparticles), and the peak will broaden due to the formation of aggregates (Fig. 9).

High-resolution XPS spectrum of the $\mathrm{Ag} 3 \mathrm{~d}$ region presented in Fig. 10 shows two deconvoluted peaks located at 368.08 and $374.08 \mathrm{eV}$ (with a spin-orbit separation of $6.0 \mathrm{eV}$ ) that can be attributed to $\mathrm{Ag} 3 \mathrm{~d}_{5 / 2}$ and $\mathrm{Ag} 3 \mathrm{~d}_{3 / 2}$, respectively [40]. For metal silver, $368.2 \mathrm{eV}$ for $\mathrm{Ag} 3 \mathrm{~d} 5 / 2$ and $374.2 \mathrm{eV}$ for $\mathrm{Ag} 3 \mathrm{~d} 3 / 2$ are reported. These results suggest a strong interaction between the carboxyl oxygen atoms in the PVP chain and Ag NPs. Furthermore, no peak corresponding to $\mathrm{Ag}_{2} \mathrm{O}(367.8 \mathrm{eV})$ or $\mathrm{AgO}(367.4 \mathrm{eV})$ is observed in the XPS spectrum of Ag NPs, which indicates that the Ag NPs are all in form of metallic Ag [41].

A primary purpose of the introducing PVP is to protect the Ag NPs from growing and agglomerating. The structures of the monomer, vinylpyrrolidone, and the repeat unit of PVP are shown in Fig. 11a and b, respectively. According to the literature [42], the main reason of PVP protecting Ag NPs is N in PVP coordinate with silver and forms the protection layer. The reactions would be like Fig. 11c. PVP preventing the Ag NPs from aggregation is 
Fig. 8 Stability of Ag NPs during 90 days

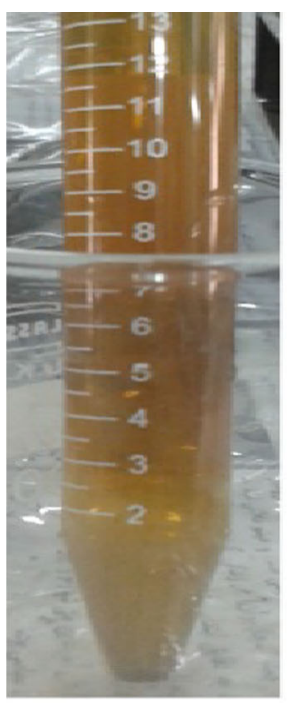

1 Day

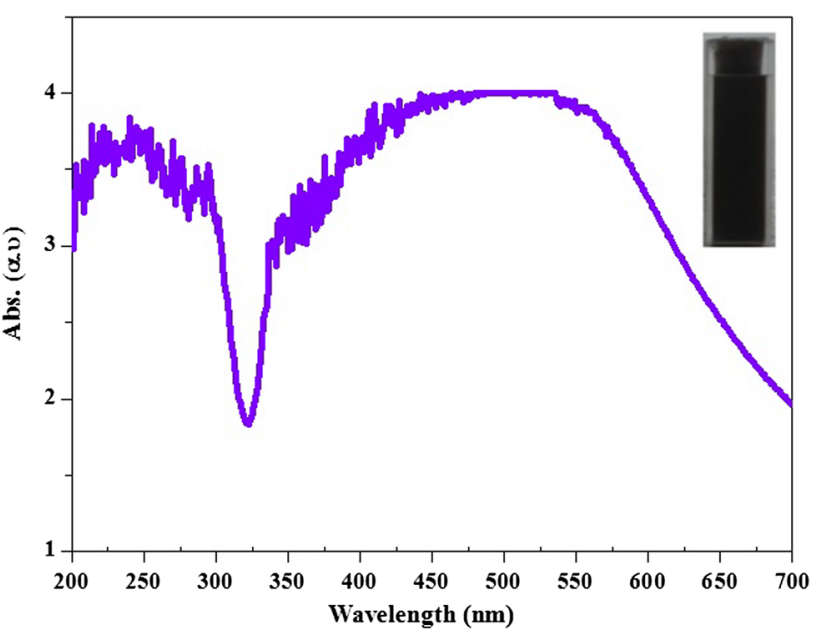

Fig. 9 UV-Vis of unstable Ag NPs after 90 days

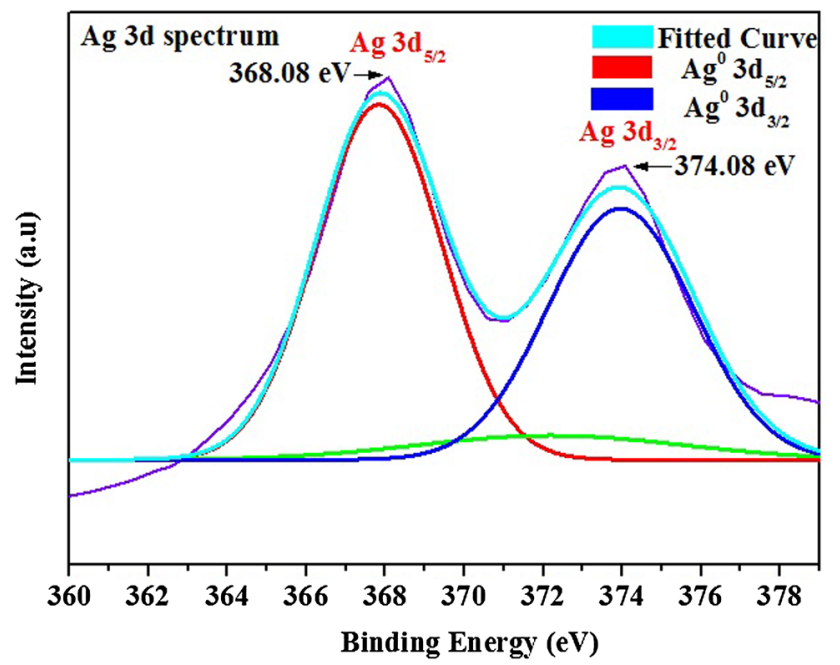

Fig. 10 XPS spectrum of Ag NPs

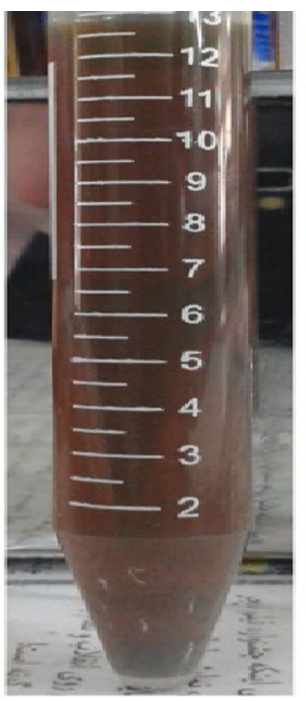

30 Days

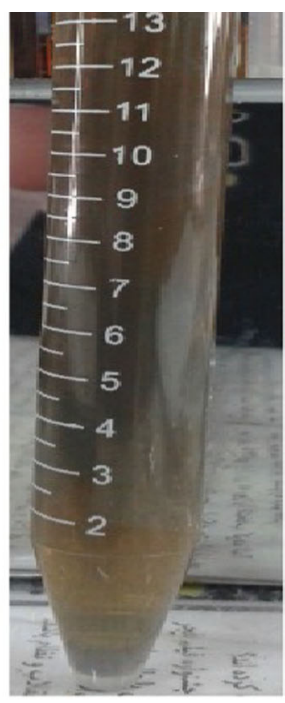

60 Days

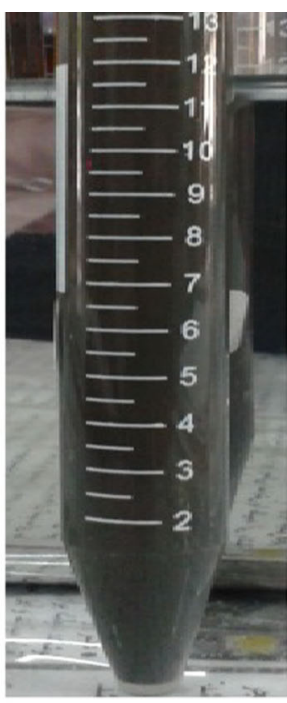

90 Days the main role of the surfactant. In fact, the steric effect arising from the long polyvinyl chain of PVP on the surface of Ag NPs may contribute to the anti-agglomeration of them.

\section{Optical studies}

Optical absorption spectra of Ag NPs measured as a function of the wavelength of incident photons are shown in Fig. 12. It seems that samples with $S=0.5$ and 1 are not totally converted to Ag NPs, as maximum peak of their adsorption is lower than other samples. In case of Ag NPs with $S=0.5$ and $S=1$, it seems that there is not enough PVP $+\mathrm{NaBH}_{4}$ to complete reduction of silver ions. For samples with $S=1.5,2,2.5$, and 3, chemical reduction is complete. The absorption maximum is almost the same, with a little shift. These results are consistent with results by Zou et al. [43], where with the increase of stabilizer amount, the position of maximum absorption wavelength slightly shifted towards red.

In the high absorption region (where $\alpha>10^{4} \mathrm{~cm}^{-1}$ ), involving interband optical transitions between valence and conduction bands, the absorption coefficient data as a function of wavelength are, determined using the Tauc formula, given by the following equation [44]:

$\alpha h v=B^{*}\left(h v-E_{g}^{\mathrm{Opt}}\right)^{m}$

where $B^{*}$ is the edge width parameter representing the materials' quality and is calculated from the linear part of this relation, $h v$ is the photon energy $(=h c / \lambda$, where $h c$ is $1239.83 \mathrm{eV}), E_{g}^{\mathrm{Opt}}$ is the optical energy gap of the material, and " $\mathrm{m}$ " is a number which characterized the mechanism of transition process. $m=1 / 2,3 / 2$, for direct transition and 
Fig. 11 a Structure of the monomer, vinylpyrrolidone. b Repeat unit of PVP. c Reaction between PVP and Ag

\section{(b)}

(a)

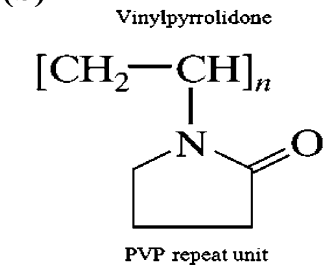

(c)

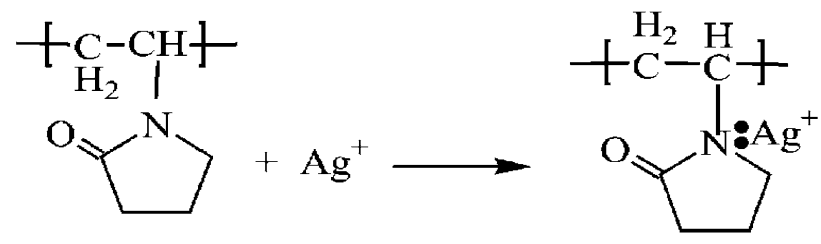

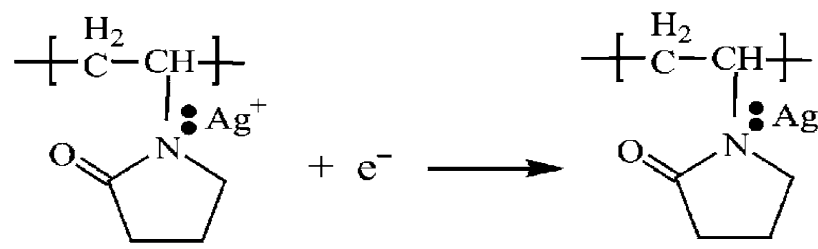

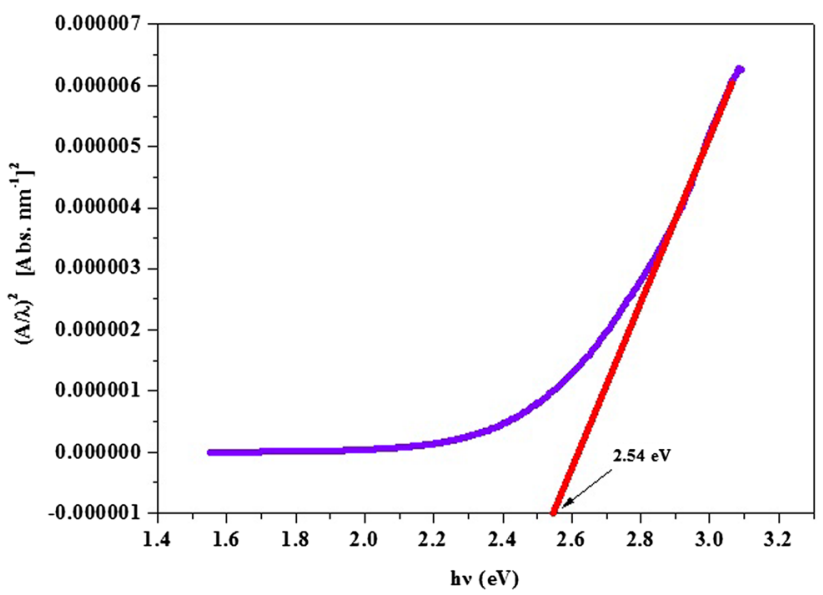

Fig. 13 Tauc plot for Ag NPs $(S=3, R=0.7)$

Figure 14 shows the variations of PL emission Ag NPs $(S=3, R=0.7)$ dispersed in water, under excitation wavelength of $355 \mathrm{~nm}$. Apparently, it can be observed that

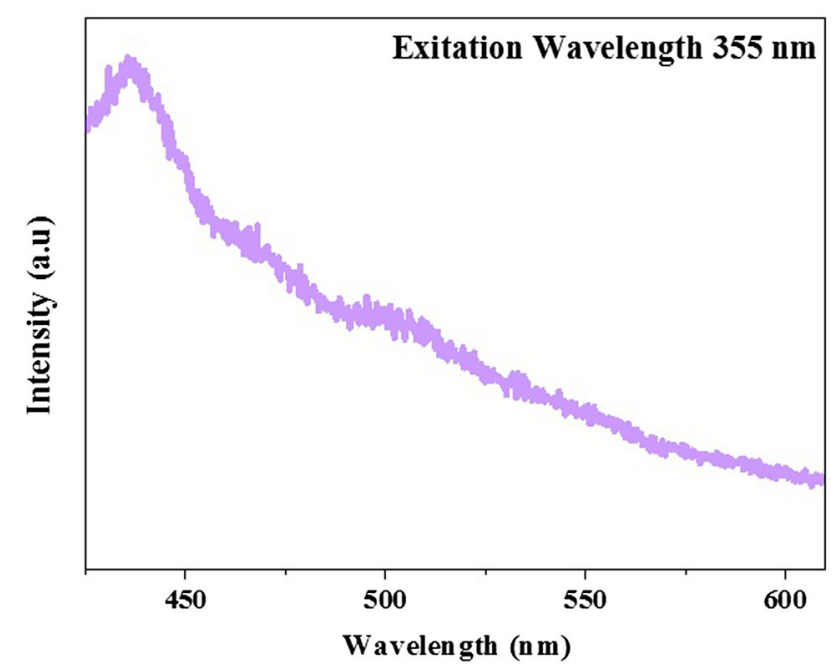

Fig. 14 Room-temperature photoluminescence emission spectrum of Ag NPs dispersed in water (Excitation wavelength was $355 \mathrm{~nm}$ ) 
the strongest emission peaks are appeared at around $440 \mathrm{~nm}$. In general, the UV emission band is originated from the direct recombination of the free excitons through an exciton-exciton collision process. In analogy with PL spectra of other noble metals, this PL peak can be assigned to radiative recombination of Fermi-level electrons and $s p$ or $d$-band holes [46].

\section{Conclusion}

In brief, we successfully prepared colloidal Ag NPs stabilized with PVP by a simple chemical reduction route using sodium borohydride as a reducing agent. Different characterization techniques, such as SEM, TEM, XRD, XPS, PSA, UV-Vis, and PL, were used to characterize synthesized Ag NPs. It was found that the average particle size can be controlled with a narrow size distribution by controlling the amount of PVP added. The particles size decreased with increasing PVP concentration. The synthesized NPs were found to be stable for 1 month, so they can be used for a long time after preparation. The sizecontrolled, well-dispersed Ag NPs prepared are capable of being dispersed in water with potential applications in dielectric and biological fields.

Acknowledgements This work was partially supported by the Iran nanotechnology council.

Open Access This article is distributed under the terms of the Creative Commons Attribution 4.0 International License (http://crea tivecommons.org/licenses/by/4.0/), which permits unrestricted use, distribution, and reproduction in any medium, provided you give appropriate credit to the original author(s) and the source, provide a link to the Creative Commons license, and indicate if changes were made.

\section{References}

1. Manikam, V.R., Cheong, K.Y., Razak, K.A.: Chemical reduction methods for synthesizing $\mathrm{Ag}$ and $\mathrm{Al}$ nanoparticles and their respective nanoalloys. Mat. Sci. Eng. B Solid. 176(3), 187-203 (2011)

2. Liu, J.F., Yu, S.J., Yin, Y.G., Chao, J.B.: Methods for separation, identification, characterization and quantification of silver nanoparticles. Trends Anal. Chem. 33, 95-106 (2012)

3. Setua, P., Chakraborty, A., Seth, D., Bhatta, M.U., Satyam, P.V., Sarkar, N.: Synthesis, optical properties, and surface enhanced Raman scattering of silver nanoparticles in nonaqueous methanol reverse micelles. J. Phys. Chem. C 111(10), 3901-3907 (2007)

4. Jiangmei, Y.A.N., Huiwang, T.A.O., Muling, Z.E.N.G., Jun, T.A.O., Zhang, S., Zhiying, Y.A.N., Wei, W.A.N.G., Jiaqiang, W.A.N.G.: PVP-capped silver nanoparticles as catalyst for oxidative coupling of thiols to disulfides. Chin. J. Catal. 30(9), 856-858 (2009)

5. Kong, H.Y., Jang, Y.S.: Antibacterial properties of novel poly(methyl methacrylate nanofiber containing silver nanoparticles. Langmuir 24, 2051-2056 (2008)
6. Mirzaei, A., Janghorban, K., Hashemi, B., Bonavita, A., Bonyani, M., Leonardi, S.G., Neri, G.: Synthesis, characterization and gas sensing properties of $\mathrm{Ag} @ \alpha-\mathrm{Fe}_{2} \mathrm{O}_{3}$ core-shell nanocomposites. Nanomaterials 5(2), 737-749 (2015)

7. Sun, L., Zhang, Z.J., Wu, Z.S., Dang, H.X.: Synthesis and characterization of DDP coated Ag nanoparticles. Mater. Sci. Eng., A 379, 378-383 (2004)

8. Pingali, K.C., Rockstraw, D.A., Deng, S.: Silver nanoparticles from ultrasonic spray pyrolysis of aqueous silver nitrate. Aerosol Sci. Tech. 39(10), 1010-1014 (2005)

9. Joseph, S., Mathew, B.: Microwave-assisted facile synthesis of silver nanoparticles in aqueous medium and investigation of their catalytic and antibacterial activities. J. Mol. Liq. 197, 346-352 (2014)

10. Shinde, M., Pawar, A., Karmakar, S., Seth, T., Raut, V., Rane, S., Bhoraska, S., Amalnerkar, D.: Uncapped silver nanoparticles synthesized by DC arc thermal plasma technique for conductor paste formulation. J. Nano. Res. 11, 2043-2047 (2009)

11. Khan, Z., Al-Thabaiti, S.A., Obaid, A.Y., Al-Youbi, A.O.: Preparation and characterization of silver nanoparticles by chemical reduction method. Colloids Surf. B 82, 513-517 (2011)

12. Yang, J., Pan, J.: Hydrothermal synthesis of silver nanoparticles by sodium alginate and their applications in surface-enhanced Raman scattering and catalysis. Acta Mater. 60, 4753-4758 (2012)

13. Lu, Y., Yu, M., Schrinner, M., Ballauff, M., Möller, M.W., Breu, J.: In situ formation of Ag nanoparticles in spherical polyacrylic acid brushes by UV irradiation. J. Phys. Chem. C 111, 7676-7681 (2007)

14. Zhang, Z., Li, V.J.: Synthesis and characterization of silver nanoparticles by a sonochemical method. Rare Metal Mater. Eng. 41, 1700-1705 (2012)

15. Nikolov, A.S., Nedyalkov, N.N., Nikov, R.G., Atanasov, P.A., Alexandrov, M.T.: Characterization of $\mathrm{Ag}$ and $\mathrm{Au}$ nanoparticles created by nanosecond pulsed laser ablation in double distilled water. Appl. Surf. Sci. 257, 5278-5282 (2011)

16. Abu-Zied, B.M., Asiri, A.M.: An investigation of the thermal decomposition of silver acetate as a precursor for nano-sized Agcatalyst. Thermochim. Acta 581, 110-117 (2014)

17. Mishra, Y.K., Mohapatra, S., Kabiraj, D., Mohanta, B., Lalla, N.P., Pivin, J.C., Avasthi, D.K.: Synthesis and characterization of $\mathrm{Ag}$ nanoparticles in silica matrix by atom beam sputtering. Scr. Mater. 56, 629-632 (2007)

18. Sun, Y., Liu, Y., Guizhe, Z., Zhang, Q.: Effects of hyperbranched poly(amido-amine)s structures on synthesis of Ag particles. J. Appl. Polym. Sci. 107, 9-13 (2008)

19. Kim, K.D., Nam Han, D., Kim, H.T.: Optimization of experimental conditions based on the Taguchi robust design for the formation of nano-sized silver particles by chemical reduction method. Chem. Eng. J. 104, 55-61 (2004)

20. Jia, Z., Sun, H., Gu, Q.: Preparation of Ag nanoparticles with triethanolamine as reducing agent and their antibacterial property. Colloids Surf. A Physicochem. Eng. Asp. 419, 174-179 (2013)

21. Zeng, J., Zheng, Y., Ryceng, M., Tao, J., Li, Z., Zhang, Q., Zhu, Y., Xi, Y.: Controlling the shapes of silver nanocrystals with different capping agents. J. Am. Chem. Soc. 132, 8552-8553 (2010)

22. Chen, Z., Gang, T., Yan, X., Li, X., Zhang, J., Wang, Y., Chen, X., Sun, Z., Zhang, K., Zhao, B., Yang, B.: Ordered silica microspheres unsymmetrically, coated with Ag nanoparticles and Ag-nanoparticles-doped polymer voids fabricated by microcontact printing and chemical reduction. Adv. Mater. 18, 924-929 (2006)

23. Chou, K.S., Ren, C.Y.: Synthesis of nanosized silver particles by chemical reduction method. Mater. Chem. Phys. 64, 241-246 (2000) 
24. Magdassi, S., Bassa, A., Vinetsky, Y., Kamyshny, A.: Silver nanoparticles as pigments for water-based ink-jet inks. Chem. Mater. 15, 2208-2217 (2003)

25. Murthy, S., Bigioni, T.P., Wang, Z.L., Khoury, J.T., Whetten, R.L.: Liquid-phase synthesis of thiol-derivatized silver nanocrystals. Mater. Lett. 30, 321-325 (1997)

26. Li, Y., Wu, Y., Ong, B.S.: Facile synthesis of silver nanoparticles useful for fabrication of high-conductivity elements for printed electronics. J. Am. Chem. Soc. 127, 3266-3267 (2005)

27. Seoudi, R., Shabaka, A., Elsayed, Z.A., Anis, B.: Effect of stabilizing agent on the morphology and optical properties of silver nanoparticles. Phys. E 44, 440-447 (2011)

28. Lee, K.J., Jun, B.H., Choi, J., Lee, Y.I., Joung, J., Oh, Y.S.: Environmentally friendly synthesis of organic-soluble silver nanoparticles for printedelectronics. Nanotechnology 18, 335601-335606 (2007)

29. Lu, Y.C., Chou, K.S.: A simple and effective route for the synthesis of nano-silver colloidal dispersions. J. Chin. Inst. Chem. Eng 39, 673-678 (2008)

30. Guo, G., Gan, W., Luo, J., Xiang, F., Zhang, J., Zhou, H., Liu, H.: Preparation and dispersive mechanism of highly dispersive ultrafine silver powder. Appl. Surf. Sci. 256, 6683-6687 (2010)

31. Wang, D., Song, C., Hu, Z., Zhou, X.: Synthesis of silver nanoparticles with flake-like shapes. Mater. Lett. 59, 1760-1763 (2005)

32. Bastús, N.G., Merkoçi, F., Piella, J., Puntes, V.: Synthesis of highly monodisperse citrate-stabilized silver nanoparticles of up to $200 \mathrm{~nm}$ : kinetic control and catalytic properties. Chem. Mater. 26(9), 2836-2846 (2014)

33. Li, H., Xia, H., Wang, D., Tao, X.: Simple synthesis of monodisperse, quasi-spherical, citrate-stabilized silver nanocrystals in water. Langmuir 29(16), 5074-5079 (2013)

34. Liu, X., Yin, Y., Gao, C.: Size-tailored synthesis of silver quasinanospheres by kinetically controlled seeded growth. Langmuir 29(33), 10559-10565 (2013)

35. Creighton, J.A., Blatchford, C.G., Albrecht, M.G.: Plasma resonance enhancement of Raman scattering by pyridine adsorbed on silver or gold sol particles of size comparable to the excitation wavelength. J. Chem. Soc. Faraday Trans. 75, 790-798 (1979)

36. Pradhan, N., Pal, A., Pal, T.: Silver nanoparticle catalyzed reduction of aromatic nitro compounds. Colloids Surf. A Physicochem. Eng. Asp. 196, 247-257 (2002)

37. Cloutier, C.R., Gyenge, E., Alfantazi, A.: Physicochemical properties of alkaline aqueous sodium metaborate solutions. J. Fuel Cell Sci. Tech. 4, 88-98 (2007)

38. Van Hyning, D.L., Klemperer, W.G., Zukoski, C.F.: Silver nanoparticle formation: predictions and verification of the aggregative growth model. Langmuir 17, 3128-3135 (2001)

39. Mirzaei, A., Janghorban, K., Hashemi, B., Bonyani, M., Leonardi, S.G., Neri, G.: Highly stable and selective ethanol sensor based on $\alpha-\mathrm{Fe}_{2} \mathrm{O}_{3}$ nanoparticles prepared by Pechini sol-gel method. Ceram. Int. 42(5), 6136-6144 (2016)

40. Ghodselahi, T., Neishaboorynejad, T., Arsalani, S.: Fabrication LSPR sensor chip of Ag NPs and their biosensor application based on interparticle coupling. Appl. Surf. Sci. 343, 194-201 (2015)

41. Li, H.J., Zhang, A.Q., Hu, Y., Sui, L., Qian, D.J., Chen, M.: Large-scale synthesis and self-organization of silver nanoparticles with Tween 80 as a reductant and stabilizer. Nanoscale Res. Lett. 7, 612-623 (2012)

42. Wang, H., Qiao, X., Chen, J., Wang, X., Ding, S.: Mechanisms of PVP in the preparation of silver nanoparticles. Mater. Chem. Phys. 94, 449-453 (2005)

43. Zou, J., Xu, Y., Hou, B., Wu, D., Sun, Y.: Controlled growth of silver nanoparticles in a hydrothermal process. China Particuol. 5(3), 206-212 (2007)

44. Ghobadi, N.: Band gap determination using absorption spectrum fitting procedure. Int. Nano Lett. 3, 1-4 (2013)

45. Khana, M.A., Kumar, S., Ahameda, M., Alrokayana, S.A., Alsalhi, M.S., Alhoshana, M., Aldwayyana, A.S.: Structural and spectroscopic studies of thin film of silver nanoparticles. Appl. Surf. Sci. 257, 10607-10612 (2011)

46. Sarkar, R., Kumbhakar, P., Mitra, A.K., Ganeev, R.A.: Synthesis and photoluminescence properties of silver nanowires. Curr. Appl. Phys. 10, 853-857 (2010) 